\title{
Healthcare system in the rural region (local government) of Nigeria: legal framework, obstacles and challenges to provide medical care
}

\author{
By Rita Dashe SELKUR*
}

\begin{abstract}
It is often said that health is wealth. That being the case then, health is an asset to be desired because a healthy man is a wealthy man equally; a healthy nation is invariably a wealthy nation. Health has been described a fundamental human right indispensable for the exercise of other human rights. This implies that the state has a responsibility for the health of her people.

Every human being is entitled to the enjoyment of the highest attainable standard of health conducive to living a life in dignity. The realization of these may be pursued through numerous, complimentary approaches, such as the formulation of health policies, or the implementation of health programmes developed by the World Health Organization (WHO) and the adoption of specific legal instruments.

Poor health inflicts great hardships on communities whereby the health status of people in the community affect their abilities to work and thus underpins the welfare of such community. This paper will attempt to examine what health care is at the rural region, the legal framework as encapsulated in the various legal instruments, obstacles and steps towards change.
\end{abstract}

\section{A. INTRODUCTION}

This paper is an analysis of the actualization of the Health system in the rural region of Nigeria, its aim is to present an account of factors responsible for the poor state of Health in this regions.

Health according to WHO is defined as a state of complete physical, mental and social wellbeing of the status of an individual, families and the community and not merely the absence of disease or infirmity (WHO, 1948) ${ }^{1}$.

It is now fully realized that the best way to provide health care services to the vast majority of abandoned underserved rural communities and urban poor is to develop effective "Primary Health Care" (PHC). The social policy throughout the whole world was to build up health system based on PHC, towards the policy objective of health for all by the year 2,000 and beyond.

* Chief magistrate court 5 Jos Plateau state.

1 www.Who.int/About/WHO/.who.who.we-are/frequently asked questions. accessed 2/11/2020. 


\section{B. EVOLUTION OF HEALTH SERVICES IN NIGERIA}

Before the advent of modern medicine, communities in the rural regions engage in total traditional medicine and like most nations, Health care was based on a trial by error to treat and discover which plant actually works for a particular disease and despite the presence of traditional healers, some diseases were treated but some were left unknown to the traditional healers and the community members which left the populace at risk of death and recurring trend of some disease. For a proper understanding of the current health situation in Nigeria, it is expedient to historicize the evolution of its healthcare system and within that framework examine some of the pitfalls that are associated with various policies.

Prior to the coming of Europeans to Nigeria, the indigenous peoples that make up the country relied entirely on indigenous herbal and fauna knowledge to resolve various health conditions. The healthcare system was based on the quality knowledge of practitioners as well as defined ways of apprenticeship to qualify as a healthcare provider ${ }^{2}$. The medical student was expected to go through years of training both in herbal knowledge, therapeutic processes, and psychosocial relations. The underlying principle of traditional medical system was a sacred calling toward the preservation of lives and to serve as a cohesive element in the society. While traditional medical practitioners may charge "fees" (in the form of barter and general reciprocity), this did not form the bases for practice as there was no fixed and clear-cut "cost" for services rendered. Within this reciprocal framework, medical practitioners were regarded as custodians of life and were accorded the utmost respect in the society. With the coming of Europeans from the fifteenth century and the subsequent introduction of Western medicine, healthcare services became monetized so that health services were rendered for a standard fee. Although the colonial government did not overtly introduce Western medicine to rural folks, the importation of Western-trained medical doctors as well as Western medicine coupled with the influx of missionaries that used Western drugs as a means of evangelism, the seeds of drastic change in traditional medicine were sown. One key factor that led to the undermining of traditional medicine and its subsequent neglect was the missionaries' association of traditional medicine with witchcraft, Satanism ${ }^{3}$, and evil. By 1960 when Nigeria gained her independence, traditional medicine is widespread throughout the world, the WHO is aware of this and had to redefine traditional medicine in $1991^{4}$ as comprising therapeutic practices that have been in existence often for hundreds of years, before the development and spread of modern scientific medicine are in use today eg Acupuncture an example of the Chinese traditional system of medicine ${ }^{5}$. Western

2 Scott Emuakpor. A 2010 The evolution of health care systems in Nigeria: which way forward in the twenty first century, Niger med J: 51:53 -65.

3 Ibid.

4 WHO 1991 " Traditional medicine and modern health care: progress report by the Director General”. Document No A44/10, march, 1991 Who Health Organization, Geneva.

5 Banner man R.H.O (1979) Acupunture: The WHO view' World Health magazine, December,pp 24 29. 
medicine had been firmly established in urban centers, while missionary activities had also penetrated some rural communities. It was this skeletal framework that incipient indigenous governments built on after independence.

\section{NATIONAL HEALTH CARE POLICY}

Health policy is usually a statement by the federal government that provides a formal and appropriate direction in health development throughout the country, these target are the federal, state and local government as well as the health institutions and health related agencies. The policy ${ }^{6}$ is formulated to obey the fundamental principle of social justice and equity that individuals should be treated equally in terms of accessibility of health services, provision of effective and affordable health care irrespective of geographical location. Made provision in areas such as:

I. National Health intervention

II. National Health information system (NHIS)

III. Fostering partnerships for Health Development

IV. National Health Research

V. National Health care laws

VI. Policing implementation; including monitory and evaluation

VII. National Health systems and management

VIII. National Health care resources

The national health policy prioritizes PHC as cornerstone of the Nigeria health system, with the sole aim of providing and accessing health care at all levels.

Health policies in Nigeria have undergone tremendous evolution in the past 60 years but without the desirable quality of healthcare delivery system in place to advance the health status of Nigerians, particularly at the local government areas. Successive governments have made concerted efforts to promote health equity and ensure unrestrained access to health services, majority of the citizens are still grappling with various health challenges. To this end, the struggles continue.

Nigeria was involved in various health plans as dictated by the federal government in the $50 \mathrm{~s}$.

The First attempt at planning the Development of Health started in 1946-1956. ${ }^{7}$ Health services and care were in urban areas and they were centralized. Curative -oriented health systems were offered and this poorly matched to the need of their people.

6 Cheld. Org/wp- content/uploads/2010/04/ Nigeria-Revised-national-Health-policy-2004. Pdf. accessed 27/9/2020.

7 https://www.Jstor.org/stable 7919537.accessed 27/9/2020. 
The second National Development Plan was between 1970 and $1974^{8}$. During this period, remote rural areas inhabited by majority of inhabitants were neglected without any form of health service.

The Third National Development Plan was between 1975 and 1980. The Basic Health Services Scheme (BHSS) was set up. The objectives included:

I. Increase access to appropriate (modern) health services by the year 1990 .

II. $\quad 35-60 \%$ by $1980 ; 80 \%$ by 1985 and $100 \%$ by 1990 .

III. Correct imbalances (inequity) in the location and distribution of health institutions, medical personnel, between preventive and curative services.

IV. Prevention and health promotion services to be integrated with curative services.

V. Provide infrastructure for all preventive programmes.

VI. Basic health units to achieve integration.

VII. Develop new cadre of PHC workers to man the health facilities to be constructed.

The BHSS concentrated on the provision of health facilities and training of health workers neglecting community participation and use of appropriate technology. The BHSS failed because of the following reasons:

I. Reliance on unsustainable structures and equipment.

II. Little community participation and inter-sectorial collaboration.

III. Selection based on political expediency.

IV. The training of health personnel were also institutional based.

V. Workers integration problems; and

VI. Same reason for preference of urban posting persisted.

The Fourth National Development Plan (1980-1985) ${ }^{10}$. During this period, various components of PHC were being implemented without integration of programmes and services. This led to fragmentation of PHC at all levels. Many international donor agencies such as UNICEF, WHO, USAID (United States Aids for International Development) embraced the programmes and most of the programmes were driven by them.

I. 1985-1992, PHC new beginning. The national primary care development agency with zonal offices in 5 states was set up, the country was also divided into health zones for effective programme implementation and supervision by the appointment of PHC coordinators in LGAs and zonal state coordinators. This was done to extend health care delivery services to rural areas, there was also the creation and training of a new staff line of Community Health Workers to carry out the PHC programmes (CHEW) aim at providing support to the national health policy as it relates to primary health care

II. By providing technical support to the planning management and implementation of PHC.

8 Ibid.

9 Ibid.

10 Ibid. 
III. Promoting and supporting the rural health system in the rural regions.

IV. From 1986; process of re-orientation of health services towards PHC approach.

V. 1987; National Health Policy was launched and the aim was to bring a comprehensive health care system, based on PHC that is promotive, protective, preventive, restorative and rehabilitative to all citizens within the available resources of that individuals and communities are assured of productivity, social well - being and enjoyment of living.

VI. In August 1987, the Federal Government launched its PHC plan.

VII. Bamako Initiative was introduced in 1988 to eliminate the out-of stock syndrome.

VIII. 1993-1999; period of low PHC activity due to political crisis. Donor agencies withdrew their funds.

After the 1978 conference $^{11}$, many countries began the process of re-organizing their health services toward the PHC approach. Nigeria also began this in 1986 with a few LGAs and extended it to all by $1990^{12}$ through the concerted effort of Dr Ramsome Kuti ${ }^{13}$.

The following was the approach taken:

I. Conducting advocacy and sensitization workshops.

II. Training of health workers and re-orientation, and setting up village health systems.

III. Setting up of development committees - village, LGA and State.

IV. Establishing health management information systems- house numbering, etc.

V. Technical and financial support to the LGAs as well as supervision.

For effective monitoring and sustainability of PHC, National Primary Health Care Development Agency was established.

\section{THE LEGAL FRAMEWORK OF THE HEALTH SYSTEM IN THE RURAL REGION OF NIGERIA.}

The Legal framework of healthcare system in the Rural region of Nigeria stems from the Federal level through to the state and to the local government.

Legal frame work ${ }^{14}$ is a broad system of rules and regulations that govern and regulate decision making, agreement etc. It can also be seen as laws that are more specific than the constitutional provision. They lay down general obligations and principles but leave out to the governing body the task of enacting further legislation and other specific measures.

In the health sector, health laws encompassed federal, state and local government laws, rules, regulations and jurisprudence pronouncement pertaining to health. These laws are meant to regulate relationship among service providers, vendors in the health industry, pa-

11 www.who.int/teams/social-determinants-of-health/declaration-of-alma-ata. Accessed 28/10/2020

12 Ransome kuti o. Who cares for the Health of Africans: the Nigerian case' international lecture series on population issues, Kaduna, Nigeria: the john o and Catherine T, Mac Arthur foundation; (1998) https://www popline.org/node/525102. Accessed 13/10/2020.

13 Then Minister for Health.

14 www.translegal.com dictionary. Accessed 18/9/2020. 
tients and the authority delivering the health service. The emphasis is usually on the operation, regulatory aspect and transactional issues.

In Nigeria some of the first set of laws promulgated by our colonial power was the $\mathrm{Pu}$ blic Health Laws and the introduction of English Common Laws that are related to health like the Quarantine Laws. On attainment of independence these laws were adopted by all the defunct regions of Nigeria as regional laws and later all the states in the country inherited the laws. An example of such laws is the

Public Health Law of Northern Region $(1957)^{15}$. This law examines the authority of government at various jurisdictional levels to improve health of the general population within societal limits and norms.

At present, health is in the concurrent list of the constitution ${ }^{16}$ of the Federal Republic of Nigeria which means that the National Assembly and the State Assemblies can enact Acts and laws in respect of health, while the Local Government Council can make rules and regulations for health.

In the light of the above both the Federal and State governments were able to enact among other laws Public Health Laws, the National Health Act $^{17}$, National and State Primary health Care Act and other related laws.

The predominant laws that guide the provision of medical care at the Local Government level are the laws establishing Primary Health Board at Local Government level and the state level law for the establishment of Private Health Establishments.

Nigeria recognizes the need for the good Health of its people and thus, committed itself to providing Health services to its citizenry by assuming obligations under international treaties $^{18}$ and domestic legislation thereby complying with specific conducts in order to achieve its goal. Nigeria is a signatory to some of these treaties, among which are:

I. International Covenant on Economic, Social and Cultural Rights (ICESCR).

II. Convention on the Elimination of all Forms of Discrimination (CERD),

III. The Convention on the Elimination of all Forms of Discrimination against Women (CEDAW) and

IV. The Convention on the Rights of the Child (CRC).

In addition, Nigeria is also a party to two health-related civil and political rights treaties, namely the International Covenant on Civil and Political Rights (ICCPR) and the Convention against Torture and Other Cruel, Inhuman or Degrading Treatment or Punishment. In addition, the country is a party to several Conventions of the international Labour Organizations, some of which contain provisions on the health of workers. Nigeria is also a party to the Geneva Conventions and Additional Protocols that prescribe rules for conduct of warfare, including health-related obligations.

15 En. Wiki pedia.org/wiki/public health law. Accessed 06/10/2020.

16 Second schedule of the 1999 constitution.

172004.

18 En.wiki pedia. Org/wiki/international-human-rights-instruments. Accessed 15/9/2020. 
Further, the country adheres to several non-binding instruments/standards that address health issues: the 1993 Vienna Declaration and Programme of Action, the Programme of Action of the 1993 UN International Conference on Population and Development and the 1995 Beijing Declaration and Platform for Action (UN Fourth World Conference on Women). At a regional level, Nigeria is a party to the African Charter on Human and Peoples' Rights (African Charter), the African Charter on the Rights and Welfare of the Child and the Protocol to the African Charter on Human and Peoples' Rights on the Rights of Women in Africa.

With respect to the applicability of these treaties within domestic framework, it is significant to note that with the exception of the African Charter, which has been incorporated into domestic legal order, no other treaty bearing on the right to health has direct application.

The legal system in the rural regions in Nigeria concerning health is very liberal; it gives right to persons to demonstrate their skills and expertise in diagnosing and proffering remedies to diseases and ailments in the community.

Although the law and regulatory bodies are in place, the legal framework is significantly weak. The practice in various communities is determined by the community health officer under the supervision of the medical health officer in the community. However, same cannot be said of the traditional medicine practitioners even when it was agreed at the Geneva Convention for traditional practitioners by the WHO that medicinal plants are of great importance to the health of individuals and communities. The Alma-ata declaration solely aims for the accommodation of proven traditional remedies in natural drugs policies and regulatory measures because it is recognized that most drugs used in modern medicine can be produced from medicinal plants available in developing countries; mostly in the rural areas. As thus, urged the inclusion of traditional healing methods in their syllables.Issues of malpractice in the rural region are hardly treated in court, negligent cases are usually accepted as the will of God and therefore, prosecution of negligent cases is rarely recorded. Moreso that the cultural component of the society believes in forgiveness.

It is noteworthy that some Regulatory bodies in place include:

I. The National Health Promotion Policy (NHPP).

II. The Medical and Dental Disciplinary Committee (MDDC)

III. The National Primary Healthcare Development Agency

IV. The National Association of Patent and Proprietary Medicine Dealers (NAPPMED), being the parent body for Patent Medicine Vendors (PMVs) and Traditional Medicine Practitioners (TMPs)

V. The Pharmacists Council of Nigeria which enacts laws distinguishing different kinds of Licenses for PMVs \& TMPs.

The National Health Promotion Policy (NHHP), of utmost significance in the implementation of Health promotion has some of the following guiding principles and values: 
I. Regulation and legislation.

II. Equality

III. Equity and social inclusion.

IV. Government accountability and responsibility, particularly at the grassroots.

V. Adapt or adopt National/State health promotion guidelines for Local use.

VI. Carry out comprehensive health promotion activities in communities including community mobilization for health actions

VII. Provide support to the health promotion and consumer rights activities at wards/ villages level.

\section{E. HEALTH POLICY AND FINANCING}

The current health policy of Nigeria is embodied in the National Health Policy and Strategy to Achieve Health for All Nigerians, introduced in 1988 and subsequently revised in 2004.

The policy indicates that local government are expected to be the main implementers of PHC policies and programmes with the federal government responsible for formulating overall policy and for monitoring and evaluation, and state government to provide logistical support to the LGA's such as personnel training, financial assistance, planning and operations. Though the 1999 constitution of Nigeria is ambiguous with regard to the authority of the LGA in providing basis services such as health care. Although, president Mohammadu Buhari recently signed an executive order granting autonomy to the local governments ${ }^{19}$, in the face of a debate over its constitutionality ${ }^{20}$, we await the implementation so that states can take up the responsibilities of the PHC properly to ensure effective PHC service delivery in the rural regions of Nigeria.

the policy seeks to improve the health of all Nigerians by devising a sustainable health system based on primary health care (PHC), that is promotive, protective, preventive, restorative and rehabilitative and which will ensure a socially and economic productive and fulfilling life to every individual ${ }^{21}$. The policy adopts WHO's strategy for realizing PHC as elaborated in the Declaration of Alma Ata.

\section{F. CONCEPT OF PRIMARY HEALTH CARE}

On the $12^{\text {th }}$ of September, 1978, a joint conference on primary health care sponsored by WHO and UNICEF in Alma Ata, Soviet Union (Russia) took place ${ }^{22}$. The conference drew

19 Guardian.ng/politics/executive- order-10-between good governance-push-and-presidential-excesses. Accessed 2/11/2020.

20 Ibid.

21 Alubo.S.Ogho" implementing Health for All in Nigeria. Problems and constraints. Health and Health care in developing countries: sociological perspectives www.jstor.org/stable/j.cH1bw1kh7. 14. Accessed 20/11/2020.

22 Declaration of alma ata op cit. pg 6. 
delegates from 134 nations Nigeria inclusive. In attendance were also representative of 67 united nations organizations, specialized agencies and Non-governmental organizations (NGO) the Alma Ata conference exploited and declared a new concept of health care delivery named "PRIMARY HEALTH CARE". There they recognized that Primary Health Care (PHC) is the key to achieving health for all (HFA). WHO expressed that PHC is a strategy and a set of activities to reach the goal of "health for all by the year 2000"23. At the conference they proposed that the basic strategy for achieving health for all was to design health systems based on PHC. WHO has identified five key elements to achieving HFA:

I. Reducing exclusion and social disparities in health (universal health coverage).

II. Organizing health services around people's needs and expectations (service delivery reforms).

III. Integrating health into all sectors (public policy reforms).

IV. Pursuing collaborative models of policy dialogue (leadership reforms).

V. Increasing stakeholder participation.

PHC was necessary because gross inequality existed between developed and developing countries and also within countries- leading to inequity and high cost of technology. Problems with accessibility to health facility, people have a right to participate individually and collectively in their own health care and sustainability of many health interventions was in doubt.

It is the first level of contact of individuals, the family and community with the national health system bringing health care as close as possible to where people live and work, and constitutes the first element of a continuing health care process. It brings health care to people's door step. In PHC, emphasis is placed on the main health problems in the community and services to be provided will include promotive, preventive, curative and rehabilitative services.

In the report of the conference referred to as Declaration of Alma-Ata, PHC is defined as "essential health care based on practical, scientifically sound and socially acceptable methods and technology made universally accessible to individuals and families in the community through their full participation and at a cost the community or country can afford to maintain at every stage of their development in the spirit of self-reliance and self-determination".

National PHC Development Agency is the governing body for PHC in Nigeria. It was established in order to manage PHC in Nigeria. The functions include support to national health policy relating to PHC, provide technical collaboration at all levels, promote PHC via advocacy, training, mobilization of resources both locally and internationally and support monitoring and evaluation. 


\section{G. ORGANIZATION AND IMPLIMENTATION OF PHC IN NIGERIA}

The goal of PHC was to provide accessible health for all by the year 2000 and beyond; i.e., providing people of the world with basic health care services. PHC is the bedrock of the country's health care policy.

According to the constitution ${ }^{24}$, Federal, State and Local Governments shall support in co-ordinated manner a three -tier system of health care viz:

I. Primary Health Care - Local Government

II. Secondary Health Care - State Government

III. Tertiary Health Care - Federal Government

In many developing countries, the organizations of health services reflect their political power structure. This is for administrative convenience though health is on the concurrent list. The three levels of health care are as follows:

\section{H. Primary Health Care}

This is the level nearest to where the people live and work. It is the first level of healthcare situated at the door post of individuals in the community both at the rural and state levels within a geographical compass of $2-3 \mathrm{~km}$ and it is suppose to be the first contact between the client and medical workers and a feedback centre after a successful referral chain completion for prompt follow up. Primary health care emphasizes more on preventive services such as:

I. Health education and community mobilization.

II. Immunization against infectious diseases.

III. Promotion of portable water supply and nutrition.

IV. Maternal and child health including family planning.

V. Early diagnosis and treatment of common diseases and injuries

VI. Promotion of food supply and proper nutrition.

VII. Implication of primary health care programmes.

VIII. Referral of cases to secondary level.

For this level to thrive, the communities must be involved in the planning, implementation and evaluation of the system in line with the Alma-Ata Declaration which states that "the people have a right to participate individually and collectively in the planning and implementation of their healthcare".

PHC seeks to address the common health problems of the people. Healthcare facilities at this level include dispensaries, health posts, clinics, health centres and comprehensive health centres, depending on the country. 
Conditions that cannot be successfully handled at the PHC level are supposed to be referred to the secondary level.. SHC is mostly disease-oriented for out-patient and in-patient care covering various specialties like surgery, internal medicine, obstetrics and gyneacology as well as pediatrics. It has in addition facilities for laboratory and X-ray related services. Health care facilities under this system are hospital-oriented, varying from district to state and national hospitals. Referrals are made from this level to the tertiary level which is the apex and facilities belonging to this group teaching and specialist hospitals. Most are owned by the national governments. While some concentrate on only one specialty (e.g. orthopedics, psychiatry, ophthalmology, etc.), others cover series in many fields. It is also expected that cases that cannot be handled at secondary level should be referred to these facilities for specialized care. In addition this level serves as training centers for high caliber man power for the health sector (e.g. doctors, pharmacists etc.), many are affiliated to universities. This tertiary level also promotes research activities because of the high level of academic output expected of the system. Tertiary facilities also work closely with others research institutes, industry as well as national and other international agencies.

Health care providers ${ }^{25}$ are expected to not only have the knowledge and skills relevant to their field but also with the ethical and legal expectations that arise out of the standard practice $^{26}$.

In the medical ethics ${ }^{27}$ it is expected that a patients right of choice of care, self governance and the right to accept or refuse treatment be respected. Health care givers are to act in the best interest of the patient in the rural region, it is evident that ethical practices among the health workers is a major challenge as you find a CHEW performing the function of a nurse at the same time doing the duties of a pharmacist. These acts, negate the principles of the health care ethics more so that the perpetrators of these acts usually go unpunished due to the weak laws and lack of political will. No doubt these acts, affect the health care service negatively ${ }^{28}$.

The PHC at the rural areas are mostly managed by CHEW (community health extension worker), community assistance and health officers with the community health officer who oversees the system and disciplines accordingly through the normal government disciplinary procedure whereby a defaulter is queried whether to be warned, suspended or dismissed. Each level has its board where cases of negligence, dereliction to duty are entertained and appropriate punishment meted.

25 Professions-networks-who.int/teams/health-workforce/health. Accessed 9/9/2020.

26 Kenelly.J.Medical ethics: four principles,two decisions,two roles and no reasons J primHealth care 2011:3:170:74. Accessed 9/9/2020.

27 Hippocratic oath-brill.com/view/journal/ajls/9/4/article-268-3.xml? language=en. Accessed 19/10/2020.

28 Diyoke.M.(2015) Attitude of health care professionals in nigeria.www.academia.edu/ng. Accessed 21/9/2020. 


\section{Obstacles And Challenges Of Legal Frame Work}

I. Poor knowledge of the acts and laws by health professionals and the public

II. Poor political commitment to implementation of the laws

III. Conflict of laws provision enacted by laws

IV. Interference by various interests during passage and signing of bills provided by the technical committee which could lead to difficulty in the enforcement of the laws when it is passed.

Challenges in the provision of medical care:

I. Lack of manpower and poor quality of personne $\mathrm{l}^{29}$

II. Poor manpower and poor development of the rural areas

III. Poor maintenance culture an provision of quality services in the PHC facilities. People rather than ask help from the PHC prefer to treat common ailments in the hospitals not minding how long the queue is before being attended to.

IV. weak involvement of partners and community in management of PHC

V. Lack of drugs and consumable in our PHC

VI. Weak monitoring and supervision of private health establishments.

VII. Lack of proper storage system

VIII. Corruption

IX. Funding

X. Reluctance of some rural dwellers to access primary healthcare even when available due to personal beliefs and traditions.

\section{WAYS TOWARD CHANGE/CONCLUSION}

According to WHO knowledge is the best weapon against the spread of disease. The declaration of Alma Ata was made to create the basis which could help to provide health generally. Nigeria should therefore not be left behind.

Access to health care is however a policy concern especially for those living in the rural areas of Nigeria. There appear on paper, policies meant to improve the health status of the people who are the most vulnerable living in the rural region of Nigeria via the PHC initiative however, in practical terms, its implementation is yet to be achieved. Primary health care facilities in the rural regions are poorly equipped and often in deplorable condition largely due to poor funding at the states and local government levels.

Though primary health care centres were established in both rural and urban areas in Nigeria with the intention of equity and ease of access to health, the rural population is however seriously underserved compared to their urban counterparts. 
Basic amenities such as transportation, electricity, medicine, supply of water which would also aid the working environment in providing quality services is equally not available as such, the essence of the PHC is not achieved.

A good health system in the rural region is that system which the people in the area respond to its laws of demand and supply. It is therefore not surprising that traditional medicine played and still plays a very important role when it comes to the healthcare of the rural people. Government policies which have not been felt in rural regions have caused a set back to the health sector of Nigeria on primary health care, in preventing diseases threatening lives of children, diarrhoea, malaria, and typhoid, among others, including maternal and child mortality.

Inadequate funding, lack of political will, poor professional quality of personal, corruption, lack of proper storage system, supply of clean water, are all stumbling blocks to achieving the goal of the Alma Ata declarations in Geneva. However, formative decisions can be made and new initiatives possible given the vision.

\section{J. RECOMMENDATIONS:}

At the end of this write up, it became obvious that there are challenges faced in the rural region. To this end, the whole system needs overhauling as there seems to be very little regard for the provision of healthcare to rural settlers. For a fact, compliance to the legal structure in place is quite minimal and disciplinary measures need be in place and promptly implemented on necessity. Government at the local government area need liaise with the Federal, State and other Stakeholders on health promotion activities and research in these rural areas. Also, they need produce quarterly and annual reports on health promotion activities within rural areas and forward such to the State health promotion division. The State government also need ensure equitable accessibility to health care delivery system across the rural area by deploying more medical and paramedical staff to the rural areas.

Rural development policies should promote the creation of enabling environment to enhance participation in modern health care delivery.

There is need for a monitory surveillance system to be In place to act quickly, in the cause of the spread of a disease thereby stopping the spread of the disease, like the corona virus outbreak which only hit hard on the urban areas because it was quickly curtailed when travels to local government areas were banned.

It is recommended that palliatives, as is pursued by the present administration, be provided by providing free health care policies for vulnerable people who suffer financial hardship instead of being used as campaign stooge of the political electorates whose promises are often not fulfilled after being elected thereby not satisfying the needs of the most vulnerable population. 


\section{BIBLIOGRAPHY}

1. Alubo.S.Ogho" implementing Health for All in Nigeria. Problems and constraints. Health and Health care in developing countries: sociological perspectives www.jstor.o rg/stable/j.cH1bw1kh7.14. Accessed 20/11/2020.

2. Banner man R.H.O (1979) Acupunture: The WHO view' World Health magazine, December,pp 24-29.

3. Cheld.Org/wp- content/uploads/2010/04/ Nigeria-Revised-national-Health-policy-2004. Pdf. accessed 27/9/2020.

4. Constitution of The Federal Republic of Nigeria: 1999 as Ammended

5. declaration of alma ata op cit. pg 6

6. Diyoke.M.(2015) Attitude of health care professionals in nigeria.www.academia.edu/ ng. Accessed 21/9/2020.

7. www.En.Wikipedia.org/wiki/public-health-law. Accessed 06/10/2020.

8. www.Guardian.ng/politics/executive- order-10-between-good-governance-push-andpresidential-excesses. Accessed 2/11/2020.

9. www.Hippocraticoath-brill.com/view/journal/ajls/9/4/article-268-3.xml? language=en. Accessed 19/10/2020.

10. https://www.Jstor.org/stable 7919537.accessed 27/9/2020.

11. Kenelly.J.Medical ethics: four principles, two decisions, two roles and no reasons $\mathrm{J}$ primHealth care 2011:3:170:74. Accessed 9/9/2020.

12. Legit.ng/1115898-primary-health-care-nigeria-challenges.html. Accessed 10/11/2020.

13. Professions-networks-who.int/teams/health-workforce/health. Accessed 9/9/2020.

14. Ransome kuti o. Who cares for the Health of Africans: the Nigerian case' international lecture series on population issues, Kaduna, Nigeria: the john o and Catherine T, Mac Arthur foundation; (1998) https://www popline.org/node/525102. Accessed 13/10/2020.

15. Scott Emuakpor. A 2010 The evolution of health care systems in Nigeria: which way forward in the twenty first century, Niger med J: 51:53 -65

16. Second schedule of the 1999 constitution.

17. Then Minister for Health.

18. WHO 1991 “ Traditional medicine and modern health care: progress report by the Director General”. Document No A44/10, march, 1991 Who Health Organization, Geneva.

19. www.En.wikipedia.Org/wiki/international-human-rights-instruments. Accessed 15/9/2020.

20. www.translegal.com dictionary. Accessed 18/9/2020.

21. www.Who.int/About/WHO/.who.who.we-are/frequently asked questions. accessed $2 / 11 / 2020$

22. www.who.int/teams/social-determinants-of-health/declaration-of-alma-ata. Accessed 28/10/2020. 